\title{
The University Hospital in Wrocław gives an example of how to live a healthy lifestyle
}

\author{
Tomasz Zatoński', Katarzyna Neubauer', Monika Kowalska², Katarzyna Zatońska' \\ 'Medical University of Wrocław, Poland \\ ¿University Hospital in Wrocław, Poland
}

\begin{abstract}
A multidisciplinary healthcare model was effective in body mass reduction in our program. A novel feature of the study was inclusion of the employees of the hospital and providing the elements of competition. A strength of the program was providing broad information about the significance of proper body weight, diet, and physical activity, which might act as a motivation factor.
\end{abstract}

KEY WORDS: The Univeristy Hospital in Wrocław, prophylactic program, non-communicable disease prevention.

ADDRESS FOR CORRESPONDENCE: Tomasz Zatoński, PhD, Department of Otolaryngology, Medical University of Wroclaw, 38 Cesarzowicka Street, 52-408 Wrocław, Poland, e-mail: tzatonski@gmail.com

\section{INTRODUCTION}

Smoking, binge drinking, diet rich in proceed food, meat, and saturated fat, and lack of physical activity are common risk factors for non-communicable diseases (diabetes, cardiovascular diseases, cancers, stroke, chronic obstructive pulmonary diseases). Western life style is also related to increased incidence of overweight and obesity, which, according to the World Health Organization, is defined as abnormal or excessive fat accumulation that may impair health. Obesity is a chronic disease. It is currently a global epidemic ("globesity"), which is reflected by recently published data about more than 1.9 billion adults being overweight (including 650 million obese) in 2016. Among a wide range of complications of obesity, malignancies have become one of the most significant. In a prospectively studied cohort of more than 900,000 U.S. adults increased body weight was related with increased death rates for all cancers combined [1]. Bhaskaran et al., in a monumental study that included a cohort of 5.24 million UK adults, have shown that higher BMI was associated with increased risk of uterine, gallbladder, kidney, cervical, thyroid cancer, leukaemia, liver, colon, ovarian, and postmenopausal breast cancer [2].

Initial therapeutic strategies in obesity are lifestyle interventions. Diet and physical activity play a key role in body weight reduction and in maintenance of the appropriate body weight. As reviewed by Soleymani et al., weight maintenance lifestyle intervention programs with proven efficacy consist of three components: diet, exercise, and behaviour, including lifestyle counselling sessions [3].

Weight loss interventions may decrease all-cause mortality in obese adults [4]. Yet, the effectiveness of non-communicable disease prevention and control using community health workers seems to be especially effective for tobacco cessation, and blood pressure and diabetes control [5]. Health literacy is described by the WHO as the cognitive and social skills that determine the motivation and ability of individuals to get access to, understand, and use information in a way that promotes and maintains good health. One of the models of health promotion includes health promoting programs organised by employers. The workplace seems to be a perfect avenue for such an intervention [6, 7]. Hospital staff are a special group, which, with their own attitude to diet, physical activity, and smoking, have a potential to promote healthy lifestyle.

\section{PROJECT}

The University Hospital in Wroclaw hosted a prophylactic program called "PrzyVitaj Fit”. Its name consists of words meaning welcome, vital, and fitness in Polish. Its 


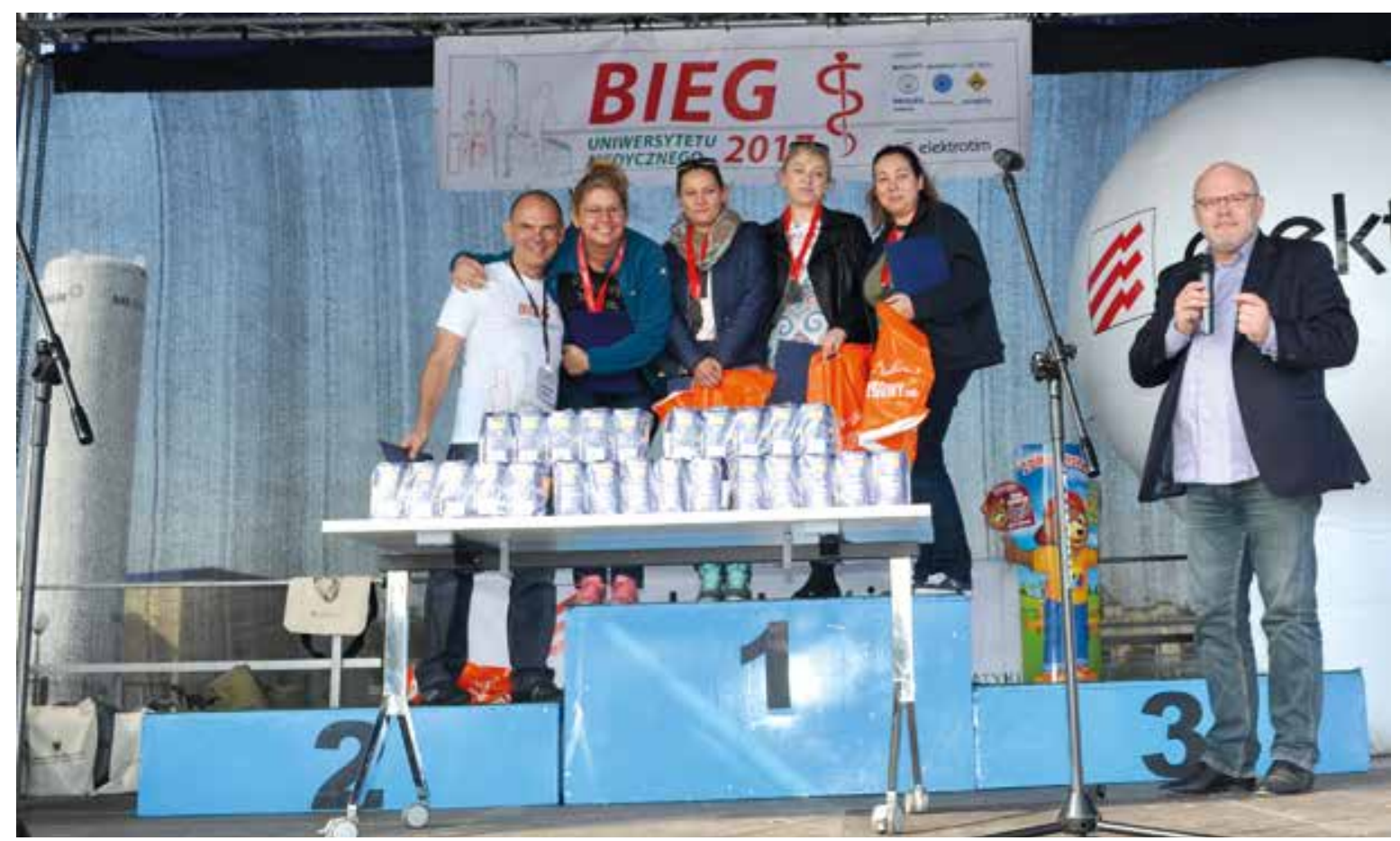

FIG. 1. Head of The University Hospital in Wroclaw Piotr Pobrotyn MD (first on the right) \& Tomasz Zatoński program founder (first on the left) reward program winning team. Every bag of sugar represents $1 \mathrm{~kg}$ of lost weight

aim was to promote healthy lifestyle, support hospital staff in rational nutrition, and help them maintain motivation for optimum mobility. Every hospital employee who had problems with overweight was eligible to apply. The action lasted half a year. There were 30 people who were divided into five teams.

At the beginning of the program each participant underwent a Bioelectrical Impedance Analysis (BIA) body composition test. The support group, consisting of physicians (internist, gastroenterologist, diabetologist, and otolaryngologist), nurses, physiotherapists, nutritionists, and clinical pharmacologists and a team of psychologists took care of participants. Each of them received nutritional guidelines. They were given a medical examination. Once a month they had to take part in consultations with specialists and workouts with a trainer. Participants in the program also had to fill in a nutrition diary. It was designed to guide him/her for two days - one in the week and the other on a day off. The participants noted all the food they ate, the number and names of the drinks they drank, the portion size, and if they had coffee or tea they had to write it down. They also included hours of sleep and physical activity.

Each participant also received a participant's index, which recorded current weight, pressure, medical examinations, and diet recommendations modified during the program. Another element of the project was education. A series of lectures was organised for participants: "Obesity and ENT Diseases", "Dietary Supplements and Healthy Eating", "Food Drug Interactions", and "Obesity and Digestive Diseases". An important element in the project was the one of team competition, which was meant to motivate them to take care of themselves. After five months, weight loss was ranged from 6 to $9 \mathrm{~kg}$ in the most motivated participants. The 15 most determined individuals lost nearly 80 kilograms combined. The final competition was held on 30 September 2017 during the Third Run of the Medical University. The results in the groups were summed up, and for the winning team, who had the greatest weight loss, the employer funded a twoday trip to an attractive Lower Silesian spa.

\section{ACKNOWLEDGEMENTS}

We would like to thank everyone involved in the programme for their generous help and engagement.

Assoc. Prof. Tomasz Zatonski, MD, PhD - scientific coordinator, program founder

Dorota Milecka, Hospital Vice President of Nursing - project coordinator

Assoc. Prof. Katarzyna Zatońska MD PhD - diabetologist Katarzyna Neubauer MD PhD - gastroenterologist

Anna Reszuta - nutritionist

Aleksandra Temler - nutritionist

Aleksandra Woch - psychologist

Natalia Staron - physiotherapist

Olga Fedorowicz - clinical pharmacologists

Magdalena Hurkacz - MD PhD - clinical pharmacologists

Aleksandra Gabrysz - nurse

Renata Podziawo - nurse

Monika Kowalska - PR

Anna Zybura - promotion

Natalia Kusztal - photography 


\section{DISCLOSURE}

Authors report no conflict of interest.

\section{References}

1. Calle EE, Rodriguez C, Walker-Thurmond K, Thun MJ. Overweight, obesity, and mortality from cancer in a prospectively studied cohort of U.S. adults. N Engl J Med 2003; 348: 16251638.

2. Bhaskaran K, Douglas I, Forbes H, et al. Body-mass index and risk of 22 specific cancers: a population-based cohort study of 5,24 million UK adults. Lancet 2014, 384: 755-765.

3. Soleymani T, Daniel S, Garvey WT. Weight maintenance: challenges, tools and strategies for primary care physicians. Obes Rev 2016; 17: 81-94.

4. Ma C, Avenell A, Bolland M, et al. Effects of weight loss interventions for adults who are obese on mortality, cardiovascular disease, and cancer: systemic review and meta-analysis. BMJ 2017; doi: 10.1136/bmj.j4849.

5. Jeet G, Thakur JS, Prinja S, Singh M. Community health workers for non-communicable diseases prevention and control in developing countries: Evidence and implications. PLoS One 2017; 12: e0180640

6. Merril R, Aldana S, Garrett J, Ross C. Effectiveness of a workplace wellness program for maintaining health and promoting healthy behaviors. J Occup Environ Med 2011; 53: 782-787.

7. Cluff LA, Lang JE, Rineer JR, et al. Training employers to implement health promotion programs: results from the CDC Work@Health ${ }^{\circledast}$ program. Am J Health Promotion 2017; doi: 10.1177/0890117117721067.

\section{AUTHORS' CONTRIBUTIONS}

TZ, KN, MK, KZ collected data and prepared the research concept of the publication, analysed data and drafted the article, contributed to the discussion and literature review, revised the paper and finally approved it. 